\title{
Effects of firefighting on semen parameters: an exploratory study
}

\author{
Michelle Engelsman1,3, Leisa-Maree L Toms², Xianyu Wang33, Andrew P W Banks³ and Debbie Blake4 \\ ${ }^{1}$ Fire and Rescue NSW, Greenacre, New South Wales, Australia \\ 2School of Public Health and Social Work, Faculty of Health, Queensland University of Technology, Kelvin Grove, Australia \\ ${ }^{3}$ QAEHS, Queensland Alliance for Environmental Health Sciences, The University of Queensland, Woolloongabba, Queensland, Australia \\ 4Repromed, Remuera, Auckland, New Zealand
}

Correspondence should be addressed to M Engelsman; Email: michelle.engelsman@fire.nsw.gov.au

\section{Lay summary}

Firefighters are occupationally exposed to heat intensities and chemical concentrations that may affect fertility. Twenty firefighters participated in an exploratory study assessing fertility of firefighters via an online survey and semen analysis. Data analysis included consideration of demographic characteristics, reproductive history and occupational exposures. Overall, firefighter semen parameters were below World Health Organisation reference values designating fertility in men. Firefighters younger than 45 years had a higher incidence of abnormal semen parameters (42\%) than those aged 45 years or greater (9\%). Increased rank and higher levels of occupational and/or personal hygiene were associated with improved semen quality. Increased frequency of fire exposure was associated with a reduction in normal forms, volume, sperm concentration and total sperm count. Sperm clumping was greater than $10 \%$ in $26 \%$ of samples, suggesting reduced semen quality. This exploratory study provides novel data that support the hypothesis of an association between semen quality and firefighter's occupational exposure to toxic environments.

Reproduction and Fertility (2021) 2 L13-L15

Firefighters are occupationally exposed to heat intensities and chemicals known to affect fertility. As part of a wider study on firefighter exposure and reproduction, firefighters were recruited to contribute a semen sample to (1) evaluate semen parameters against fertility standards and other cohorts (2) assess demographic, exposure and reproductive history against semen analysis results, and (3) consider how occupational exposures may affect semen parameters. Following Human Ethics Approval through The University of Queensland, 20 firefighters contributed 23 semen samples at specified pathology centres. Semen samples were analysed in line with the World Health Organisation (WHO) methodology. Not all samples were analysed within $60 \mathrm{~min}$ due to unspecified pathology centre delays. Semen analysis included viscosity, liquefaction, agglutination, volume, sperm concentration, progressive motile, total motile, immotile, and normal forms.
Sample data were checked for completeness, consistency, accuracy and validity. Descriptive statistics were performed to summarise the data. Pearson's correlations (two-tailed) were used to investigate the relationship between firefighter survey results and sample characteristics. Mann-Whitney $U$-tests were performed to determine statistical significance. Participants' demographic and semen data, including WHO reference data for fertile men (WHO 2010), are shown in Table 1.

Across parameters, semen characteristics were grouped in relation to time to analysis (analysis within, or greater than, $60 \mathrm{~min}$ ). No statistically significant differences were found based on time to analysis. Data were stratified by age (less than and greater than 45 years of age) based around research demonstrating statistically significant reductions in semen parameters with increasing age brackets above 45 years (Hellstrom et al. 2006). Younger participants (under 45 years of age) presented non-significant mean decreases in 
Table 1 Characteristics of participants in semen exploratory study, with WHO (2010) reference ranges presented. Data are presented as $n$ or as mean \pm S.D.

\begin{tabular}{|c|c|c|}
\hline Characteristics & Values & WHO 2010 \\
\hline Total participants & 20 & \\
\hline Age, years* & $45 \pm 10$ & \\
\hline$<45$ & 11 & \\
\hline$\geq 45$ & 9 & \\
\hline Active duty (current fire exposure) & 18 & \\
\hline Rank firefighter & 18 & \\
\hline Rank station officer/captain & 2 & \\
\hline Full-time firefighter & 16 & \\
\hline Part-time firefighter & 4 & \\
\hline Years in job* & $20 \pm 10$ & \\
\hline Tobacco smoker & 0 & \\
\hline Abstinence in days & $3.8 \pm 1.1$ & \\
\hline Minutes to analysis & $104 \pm 66$ & \\
\hline Successfully conceived at least 11 child & 15 & \\
\hline Unable to conceive in 1 or more attempts & 1 & \\
\hline Difficulty conceiving & 6 & \\
\hline Unknown cause & 4 & \\
\hline Abnormal semen parameters & 1 & \\
\hline Hormone imbalance & 1 & \\
\hline Underwent IVF in any instance & 4 & \\
\hline Reported time to pregnancy & 7 & \\
\hline$\leq 12$ months & 5 & \\
\hline$>12$ months & 2 & \\
\hline Experienced miscarriage(s) & 3 & \\
\hline Negative pregnancy or birth outcomes ${ }^{\dagger}$ & 7 & \\
\hline \multicolumn{3}{|l|}{ Semen volume } \\
\hline 5 th\% & 0.6 & 1.5 \\
\hline 50 th\% & 2.0 & 3.7 \\
\hline 95th\% & 5.0 & 6.8 \\
\hline \multicolumn{3}{|l|}{ Sperm concentration $10^{6} / \mathrm{mL}$} \\
\hline 5 th\% & 12 & 15 \\
\hline 50 th\% & 73 & 73 \\
\hline 95th\% & 180 & 210 \\
\hline \multicolumn{3}{|l|}{ Total sperm count $10^{6} / \mathrm{M}$} \\
\hline 5 th $\%$ & 33 & 39 \\
\hline 50th\% & 150 & 260 \\
\hline 95th\% & 450 & 800 \\
\hline \multicolumn{3}{|l|}{ Total motile \% } \\
\hline 5 th\% & 34 & 40 \\
\hline 50 th\% & 56 & 61 \\
\hline 95th\% & 73 & 78 \\
\hline \multicolumn{3}{|l|}{ Progressive motility \% } \\
\hline 5 th\% & 16 & 32 \\
\hline 50th\% & 46 & 55 \\
\hline 95th\% & 71 & 72 \\
\hline \multicolumn{3}{|l|}{ Normal forms \% } \\
\hline 5 th $\%$ & 3.1 & 4 \\
\hline 50th\% & 9.0 & 15 \\
\hline 95th\% & 21 & 44 \\
\hline
\end{tabular}

*Age and duration of employment data were collected in 5-year increments (employment had one option of $<1$ year). To calculate the crude mean, the midpoint of each bracket was utilised. **These data are from firefighters self-reporting via the Stage 1 survey. ${ }^{\dagger}$ Negative birth outcomes include miscarriage, still birth, pre-term birth, low birth weight, astigmatisms, attention deficit hyperactivity disorder (ADHD), club foot, dyspraxia, and asthma.

https://raf.bioscientifica.com

https://doi.org/10.1530/RAF-20-0070 (c) 2021 The authors Published by Bioscientifica Ltd total motility ( $50 \%$ vs $61 \%$ ), rapid progression ( $40 \%$ vs $53 \%$ ) and morphology ( $8.7 \%$ vs $12 \%)$ when compared with those aged 45 years or greater. Frequency of exposure (less than or greater than weekly) was associated with non-significant mean decreases in morphology ( $7.8 \%$ vs $12 \%)$, volume ( 2.2 $\mathrm{mL}$ vs $2.8 \mathrm{~mL})$, sperm concentration $(80 \mathrm{M} / \mathrm{mL}$ vs $87 \mathrm{M} / \mathrm{mL})$ and total sperm count ( $150 \mathrm{M} /$ ejaculate vs $220 \mathrm{M} /$ ejaculate).

Overall, firefighter semen parameters were below WHO reference values in numerous categories. Positive correlations $(P<0.05)$ in semen quality were found across semen parameters with increased rank, with increased use of breathing apparatus across fire types, and with both increased showering post fire incidents and hand washing throughout the shift. Negative associations were detected for normal forms, volume, sperm concentration and total sperm count with increasing frequency of fire exposure. Sperm agglutination was $>10 \%$ in $26 \%$ of samples.

This is the first investigation published on Australian firefighter sperm quality. Internationally, studies exist on firefighter reproductive history, with suggested links to toxic work (Petersen et al. 2019). There is, however, a scarcity of data on firefighter semen parameters. This exploratory study provides novel data that support the hypothesis that there is indeed an association between semen quality and firefighter's occupational exposure to toxic environments. These results will add value to the design of a well-powered and targeted investigation aimed at maintaining and improving the health and well-being of firefighters, their families and offspring.

\section{Declaration of interest}

There is no conflict of interest present within this research work. Although the lead researcher undertakes research while having a primary employment within a fire service, a comprehensive intellectual property, confidentiality and data sharing agreement has been signed between the lead researcher, employer and the University of Queensland, reducing any possibility of a conflict of interest.

\section{Funding}

This work is funded predominantly by the Community Safety Directorate of Fire \& Rescue NSW (FRNSW), Women and Firefighting Australasia (WAFA), and through substantial in-kind support by SafeWork NSW and TestSafe Laboratories.

\section{Author contribution statement}

M E led study conception, the management of external relationships, participant recruitment, data analysis, and manuscript drafting, review and editing. L M T and XW were involved in study progression post inception, manuscript shaping, editing and review, and providing expert guidance. A P W B was involved in results analysis, manuscript shaping and editing. D B was involved in data analysis, manuscript shaping, editing and review, and providing expert guidance. All authors were involved in the discussion of results and consideration of limitations.
This work is licensed under a Creative Commons Attribution 4.0 International License.

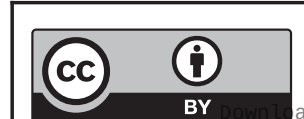

ded from Bioscientifica.com at 04/26/2023 06:23:36AM 


\begin{tabular}{l|l|l|l}
$\begin{array}{l}\text { Reproduction } \\
\text { \& Fertility }\end{array}$ & M Engelsman et al. & $\begin{array}{l}\text { Effects of firefighting on } \\
\text { semen parameters }\end{array}$ & L15 \\
\hline
\end{tabular}

\section{Acknowledgements}

The authors thank the participants involved in this exploratory study for their time, interest and participation. The authors also thank Associate Professor Cecilia Sjoblom for her expert and generous guidance, support and advice in the development of this manuscript and Professor Jochen Mueller for his expert supervision and guidance.

\section{References}

Hellstrom WJG, Overstreet JW, Sikka SC, Denne J, Ahuja S, Hoover AM, Sides GD, Cordell WH, Harrison LM \&

Whitaker JS 2006 Semen and sperm reference ranges for men 45 years of age and older. Journal of Andrology 27 421-428. (https://doi. org/10.2164/jandrol.05156)

Petersen KU, Hansen J, Ebbehoej NE \& Bonde JP 2019 Infertility in a cohort of male Danish firefighters: a register-based study. American Journal of Epidemiology 188 339-346. (https://doi.org/10.1093/aje/ kwy235)

WHO 2010 WHO Laboratory Manual for the Examination and Processing of Human Semen, Fifth edition. World Health Organization. (available at https://www.who.int/publications/i/item/9789241547789)

Received in final form 27 January 2021

Accepted 16 February 2021

Accepted Manuscript published online 16 February 2021 (c) 2021 The authors Published by Bioscientifica Ltd
This work is licensed under a Creative Commons Attribution 4.0 International License.

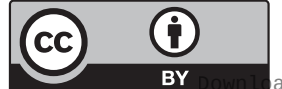

aded from Bioscientifica.com at 04/26/2023 06:23:36AM 